\title{
EFICIÊNCIA DE SISTEMAS DE IRRIGAÇÃO EM MUDAS DE ESPÉCIES FLORESTAIS NATIVAS PRODUZIDAS EM TUBETES
}

\section{IRRIGATION EFFICIENCY ON NATIVE FOREST SEEDLINGS GROWN IN RECIPIENT TUBES}

\author{
Michael Silveira Thebaldi ${ }^{1}$ Luiz Antonio Lima ${ }^{2}$ Antonio Carlos da Silva ${ }^{3}$ \\ Matheus de Figueiredo Braga Colares ${ }^{4}$ Pedro Luiz Terra Lima ${ }^{5}$
}

\begin{abstract}
RESUMO
A baixa qualidade de mudas pode advir de problemas na irrigação e/ou nutrição das mudas em sua fase de formação em viveiros. Em relação à irrigação, problemas podem surgir referentes à má distribuição da água ou mesmo seu manejo, levando ao deficit ou ao excesso de irrigação, enquanto o excesso pode lixiviar nutrientes, o deficit pode prejudicar o desenvolvimento da planta. Assim, o presente trabalho teve como objetivos avaliar a eficiência de irrigação de um sistema de irrigação por microaspersão já instalado em um viveiro de mudas de espécies florestais e também avaliar a eficiência de um sistema de subirrigação de mudas florestais nativas cultivadas em tubetes. A avaliação da eficiência da microaspersão foi realizada em um viveiro de mudas de espécies nativas florestais na cidade de Itutinga - MG, o delineamento utilizado foi o inteiramente casualizado (DIC) em esquema de parcelas subdivididas, estando o equipamento de irrigação na parcela (três níveis: MA-20, Rondo e Inverted Rotor Spray) e três espécies florestais na subparcela. Na avaliação de eficiência em tubetes de $300 \mathrm{~cm}^{3}$, as categorias da subparcela foram: araucária (Araucaria angustifolia (Bert.) O. Ktze.), jerivá (Syagrus romanzoffiana (Cham.) Glassman) e cutieira (Joannesia princeps Vell.). Em tubetes de $110 \mathrm{~cm}^{3}$ os três níveis da subparcela foram as espécies: mutamba (Guazuma ulmifolia Lam.), angico-vermelho (Anadenanthera macrocarpa Benth.) e peroba-rosa (Aspidosperma polyneuron Muell.). A avaliação da eficiência da subirrigação foi realizada em uma estufa localizada na Universidade Federal de Lavras, em dois tanques de subirrigação em três repetições. As maiores eficiências de aplicação foram obtidas para o emissor modelo MA-20. Não houve diferenças significativas entre a eficiência de aplicação dos microaspersores em relação às espécies estudadas, em ambos os tubetes. A eficiência de irrigação no tanque de tubetes de $300 \mathrm{~cm}^{3}$ foi $90,42 \%$, enquanto para tubetes de $110 \mathrm{~cm}^{3}$ foi $92,17 \%$. Os tanques de subirrigação mostraram-se como alternativa interessante para irrigação de mudas das espécies florestais testadas, apresentando alta eficiência para os dois tamanhos de tubetes avaliados.
\end{abstract}

Palavras-chave: viveiro; subirrigação; microaspersão.

\begin{abstract}
Seedlings low quality can result due to problems in irrigation and/or nutrition of seedlings in their nursery phase. Regarding irrigation, problems can arise related to low uniformity of water application or its management, leading to lack or excess of water. While the excess can leach nutrients, the deficit can affect plant growth. Thus, this work had as objective to evaluate irrigation efficiency of a microsprinkler irrigation system at a forest native species nursery and also at sub-irrigation of forest native species being raised in recipient tubes The microsplinkler irrigation efficiency evaluation was performed in a native forest nursery at Itutinga - MG city, held in completely randomized design in split plots scheme, with the irrigation equipment

1 Engenheiro Agrícola, DSc., Professor Titular, Centro Universitário de Formiga - MG, Avenida Doutor Arnaldo de Senna, 328, Água Vermelha, CEP 35570-000, Formiga (MG), Brasil. msthebaldi@uniformg.edu.br

2 Engenheiro Agrícola, Ph.D., Professor Associado, Universidade Federal de Lavras, Campus Universitário, Caixa Postal 3037, CEP 37200-000, Lavras (MG), Brasil. lalima@deg.ufla.br

3 Engenheiro Agrícola, DSc., Professor, Universidade José do Rosário Vellano, Rodovia MG 179, km 0, Câmpus Universitário CEP 37130-000, Alfenas (MG), Brasil. engcarlinhos@hotmail.com

4 Agrônomo, DSc., Professor Substituto, Instituto Federal do Norte de Minas Gerais, Fazenda São Geraldo s/n, Bom Jardim, Januária (MG) CEP 39480-000, Brasil. matheus-colares@hotmail.com

5 Engenheiro Agrícola, DSc., Professor, Centro Universitário de Lavras, Rua Padre José Poggel, 506, Centenário, CEP 37200-000, Lavras (MG), Brasil. pedroterralima@yahoo.com.br
\end{abstract}


on the plot (three levels: MA-20, Rondo and Inverted Rotor Spray) and three forest species on subplot. For efficiency evaluation in large tubes, the categories of subplot were: Araucaria angustifolia (Bert.) O. Ktze., Syagrus romanzoffiana (Cham.) Glassman and Joannesia princeps Vell. In small tubes, the three levels of subplots were the species: Guazuma ulmifolia Lam., Anadenanthera macrocarpa Benth. and Aspidosperma polyneuron Muell. The sub-irrigation efficiency evaluation was conducted in a greenhouse located at UFLA, in two sub-irrigation tanks with three replications, through calculation of uniformity coefficients for each sub-irrigated species, done in three replications. The largest application efficiency was obtained for the MA20 emitter. There were no significant differences between the application efficiency of the emitters relative to the cultivated species, in both tube sizes. The efficiency in $300 \mathrm{~cm}^{3}$ tubes irrigation tank was $90.42 \%$, while for $110 \mathrm{~cm}^{3}$ tubes it was $92.17 \%$. Sub-irrigation tanks proved to be an interesting alternative for irrigation of the tested forest species seedlings, with high efficiency for both tubes sizes.

Keywords: nursery; sub-irrigation; microsplinkler.

\section{INTRODUÇÃO}

A demanda por produtos de origem florestal aumentou sensivelmente nas últimas décadas, levando a silvicultura a buscar alternativas que pressupõem altas produtividades (BOLFE et al., 2004), como a melhoria da qualidade das mudas produzidas.

Uma das técnicas utilizadas em viveiros para a produção de mudas é a irrigação, que se destaca por permitir a produção durante todo o ano, que as sementes utilizem todo seu potencial genético e por gerar homogeneidade na produção. Isto só é conseguido, entretanto, se o sistema for bem dimensionado e operado. A avaliação de sistemas de irrigação logo após a implantação em campo é importante para verificar se o desempenho está de acordo com o estabelecido em projeto, possibilitando, quando necessário, a realização de ajustes para melhorá-lo (SOCCOL et al., 2002).

A eficiência de um sistema de irrigação, definida como a relação entre a quantidade de água armazenada no sistema radicular e a quantidade total aplicada, representa a razão entre as quantidades de água envolvidas no processo de irrigação (FRIZZONE; DOURADO NETO, 2003). Trata-se de um dos parâmetros mais utilizados para avaliar a irrigação. Essa relação sempre será menor que um, pois durante ou após a atividade de irrigação ocorrem perdas no processo de aplicação e/ou por drenagem (STAMATO JÚNIOR, 2007).

A irrigação em viveiros emprega, em geral, sistemas de irrigação por gotejamento, microaspersão ou microaspersão invertida, sendo o último bastante utilizado. Porém, uma desvantagem significante desta última, é que a irrigação sobre copa pode ser bastante ineficiente. Dumroese et al. (1995) citam que em um viveiro de reflorestamento, perde-se de $49 \%$ a $72 \%$ da água aplicada.

Em função da produção em viveiros e casas de vegetação usar maiores taxas de fertilização que em outros cultivos (MOLITOR, 1990), a água perdida pode ter uma quantidade significativa de fertilizante não utilizado (JUNTENEN et al., 2002; DUMROESE et al., 2005) e ser uma fonte potencial de poluição da água subsuperficial e superficial (DUMROESE et al., 2006) nas proximidades do viveiro.

Assim, a subirrigação apresenta-se como solução relevante no que se refere ao ganho em eficiência de uso da água. Quando a irrigação é completada, a água não utilizada é drenada de volta ao reservatório para posterior recirculação pelo sistema (STRONG et al., 1997; DUMROESE et al., 2006). Já que o sistema é fechado, uma redução em $86 \%$ de uso da água foi conseguida em subirrigação comparado com irrigação sobrecopa em culturas alimentares (AHMED; CRESSWELL; HAIGH, 2000), e a perda de fertilizantes para o solo é, praticamente, eliminada, já que a água lixiviada é recirculada, impedindo que fertilizantes e pesticidas atinjam os lençóis superficiais e profundos. Podese ressaltar ainda a redução no consumo de energia elétrica (CHANSEETIS et al. 2001; TOSHIAKI et al., 2004).

Em vista do exposto, o presente trabalho teve como objetivos avaliar a eficiência de irrigação de um sistema de irrigação por microaspersão já instalado em um viveiro de mudas de espécies florestais e também avaliar a eficiência de um sistema de subirrigação de mudas florestais nativas cultivadas em tubetes. 


\section{MATERIAL E MÉTODOS}

\section{Eficiência da microaspersão}

$\mathrm{Na}$ avaliação de eficiência em tubetes grandes $\left(300 \mathrm{~cm}^{3}\right)$, as espécies avaliadas foram: araucária (Araucaria angustifolia (Bert.) O. Ktze.), jerivá (Syagrus romanzoffiana (Cham.) Glassman) e cutieira (Joannesia princeps Vell.). Na avaliação de tubetes pequenos $\left(110 \mathrm{~cm}^{3}\right)$ os três níveis de espécies foram: mutamba (Guazuma ulmifolia Lam.), peroba-rosa (Aspidosperma polyneuron Muell.) e angico-vermelho (Anadenanthera macrocarpa Benth.). Os equipamentos de irrigação testados foram os microaspersores MEC - PREC MA-20, Plastro Rondo e Antelco Inverted Rotor Spray, mostrados na Figura 1.

As mudas se encontravam em fase final de viveiro, ou seja, em pré-plantio, com idade entre 9 e 12 meses. As espécies araucária, jerivá e cutieira possuíam área foliar de $233,36 \mathrm{~cm}^{2}, 54,59$ $\mathrm{cm}^{2}$ e $83,15 \mathrm{~cm}^{2}$, respectivamente. Já as espécies mutamba, peroba-rosa e angico-vermelho possuíam $32,65 \mathrm{~cm}^{2}, 54,61 \mathrm{~cm}^{2}$ e $31,49 \mathrm{~cm}^{2}$ de área foliar, respectivamente.

O enchimento dos tubetes com substrato foi feito de maneira manual. O substrato utilizado foi o Tropstrato Florestal ${ }^{\circledR}$ fabricado pela empresa Vida Verde, composto por fibra de coco, vermiculita,

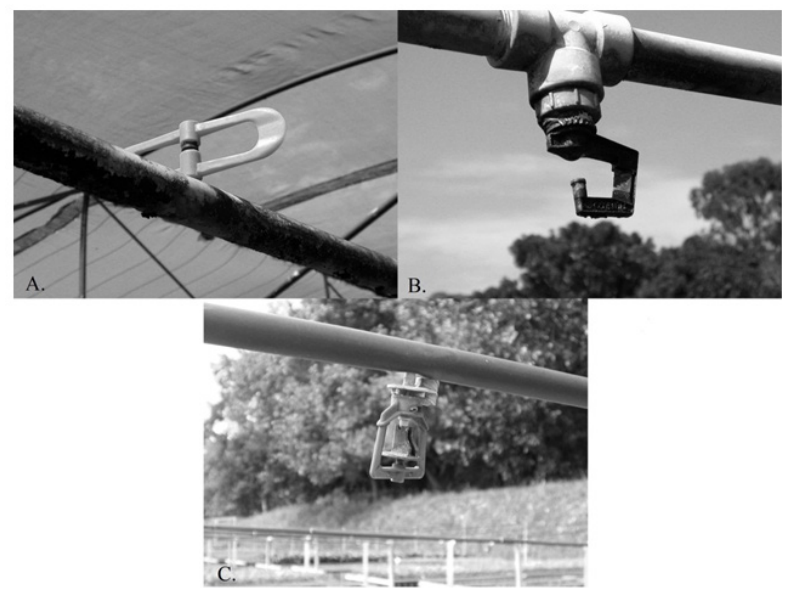

FIGURA 1: Microaspersores MA-20 (A), Inverted Rotor Spray (B) e Rondo (C), instalados no viveiro de mudas florestais em Itutinga - MG.

FIGURE 1: Microsprinklers MA-20 (A), Inverted Rotor Spray (B) and Rondo (C), installed in the forest nursery at Itutinga - MG. carvão vegetal e casca de pinus em proporções não informadas pelo fabricante.

Dentro das áreas ocupadas pelas espécies avaliadas, foram selecionadas três bandejas ao acaso, tanto para o tubete pequeno (bandeja de $0,263 \mathrm{~m}^{2}$ com 108 espaços) quanto para o tubete grande (bandeja de $0,246 \mathrm{~m}^{2}$ com 54 espaços). As bandejas encontravam-se preenchidas com metade da capacidade máxima de tubetes.

Nos tubetes das áreas amostrais foram fixados sacos plásticos $(0,24 \mathrm{~m} \times 0,05 \mathrm{~m})$ na sua parte inferior para a coleta do excedente de solução percolada através do recipiente. No chão, abaixo de cada área amostral, foram colocadas bandejas plásticas para coleta da água que pudesse passar pelos espaços intersticiais das bandejas.

Após a irrigação, foi esperado o tempo de 30 minutos para que se assegurasse que toda a água passível de drenagem dos tubetes chegasse aos sacos plásticos. Para facilitar a operação e minimizar a possibilidade de erros de leitura, uma amostra de trinta sacos plásticos foi pesada, sendo a média destes descontada do peso total do conjunto saco plástico e água drenada. A massa de água, em gramas, foi convertida em litros.

Assim, para determinação da lâmina perdida de água na irrigação, foi utilizada a Equação 1. A avaliação da eficiência de aplicação foi realizada segundo metodologia adaptada de Salvador (2010).

$$
\mathrm{L}_{\mathrm{p}}=\left(\frac{\mathrm{V} \mathrm{p}_{\text {direto }}}{\mathrm{A}_{\text {bandejacoletora }}}+\frac{\mathrm{V} \mathrm{p}_{\text {percolação }}}{\mathrm{At} \mathrm{t}_{\text {tubetes }}}\right)
$$

Em que: $\mathrm{L}_{\mathrm{p}}=$ lâmina perdida $(\mathrm{mm}) ; \mathrm{Vp}_{\text {direto }}=$ volume médio perdido diretamente, obtido pela média dos volumes coletados nas bandejas instaladas abaixo das três áreas amostrais (L); $\mathrm{A}_{\text {bandejacoletora }}=$ área da bandeja coletora posicionada abaixo das áreas amostrais $\left(\mathrm{m}^{2}\right) ; \mathrm{Vp}_{\text {percolacão }}=$ volume médio perdido por percolação, obtido pela média dos volumes totais coletados nos sacos plásticos aderidos aos tubetes das três áreas amostrais $(\mathrm{L}) ; \mathrm{At}_{\text {tubetes }}=$ área do diâmetro superior do tubete, multiplicado pelo número de tubetes de cada área amostral $\left(\mathrm{m}^{2}\right)$.

A lâmina aplicada foi obtida posicionandose, na mesma área em que foram coletadas as lâminas perdidas, tanto por percolação e quanto de maneira direta, uma bandeja de plástico sobre a bancada de mudas, recolhendo o volume irrigado sem nenhuma interferência. A lâmina aplicada, por área amostral, foi calculada pela Equação 2. 


$$
\mathrm{L}_{\mathrm{a}}=\frac{\mathrm{V}_{\mathrm{a}}}{\mathrm{A}_{\text {bandejacoletora }}}
$$

Em que: $\mathrm{L}_{\mathrm{a}}=$ lâmina aplicada por área amostral $(\mathrm{mm}) ; \mathrm{V}_{\mathrm{a}}=$ volume aplicado por área amostral (L).

$\mathrm{O}$ tempo de irrigação no setor com o emissor MA-20 foi de três minutos, no setor com o microaspersor IRS foi de quatro minutos e no setor com o microaspersor Rondo, seis minutos, estes estipulados pelo irrigante do viveiro em sua rotina normal de trabalho.

Para a determinação da perda de água na irrigação, foi empregada a Equação 3.

$$
\mathrm{P}=\frac{\mathrm{L}_{\mathrm{p}}}{\mathrm{L}_{\mathrm{a}}} \times 100
$$

Em que: $\mathrm{P}=$ perda total de água (\%).

Finalmente, a eficiência de aplicação da irrigação pode ser calculada pela Equação 4.

$$
\mathrm{Ea}=100-\mathrm{P}
$$

Em que: Ea = eficiência de aplicação (\%).

Para fins de análise estatística, os valores obtidos foram submetidos à transformação arco seno da raiz quadrada, por se tratarem de dados de porcentagem. $\mathrm{O}$ experimento foi realizado em delineamento inteiramente casualizado em esquema de Parcelas Subdivididas, estando o equipamento de irrigação na parcela (três níveis: MEC - PREC MA-20, Plastro Rondo e Antelco Inverted Rotor Spray) e as espécies florestais na subparcela. Três repetições foram coletadas, representadas por áreas amostrais sob um mesmo equipamento de irrigação combinado à espécie florestal.

\section{Eficiência da subirrigação}

A subirrigação foi realizada utilizando dois tanques, um para bandejas de tubetes pequenos $\left(110 \mathrm{~cm}^{3}\right)$ e outro para bandejas de tubetes grandes $\left(300 \mathrm{~cm}^{3}\right)$, com dimensões de $1,65 \mathrm{~m} \mathrm{x} 2,55 \mathrm{~m} \mathrm{e}$ $1,60 \mathrm{~m} \times 2,50 \mathrm{~m}$, respectivamente. Ambos os tanques possuíam $0,2 \mathrm{~m}$ de profundidade e altura total de $1,10 \mathrm{~m}$, construídos de blocos de concreto (dimensões de $0,40 \mathrm{~m} \times 0,20 \mathrm{~m} \times 0,15 \mathrm{~m}$ ).

Encontram-se na Figura 2 os detalhes dos tanques de subirrigação como: vista lateral (2A), tubulação de entrada de água com hidrômetro (2B), tubulação de saída de água e reservatórios para bombeamento e armazenamento da água drenada (2C) e vista lateral superior do tanque para tubetes pequenos (2D).

Em cada bandeja foram utilizadas dezoito plantas cultivadas em tubetes grandes e trinta e seis plantas em tubetes pequenos, utilizando-se as mesmas espécies avaliadas na irrigação por microaspersão.

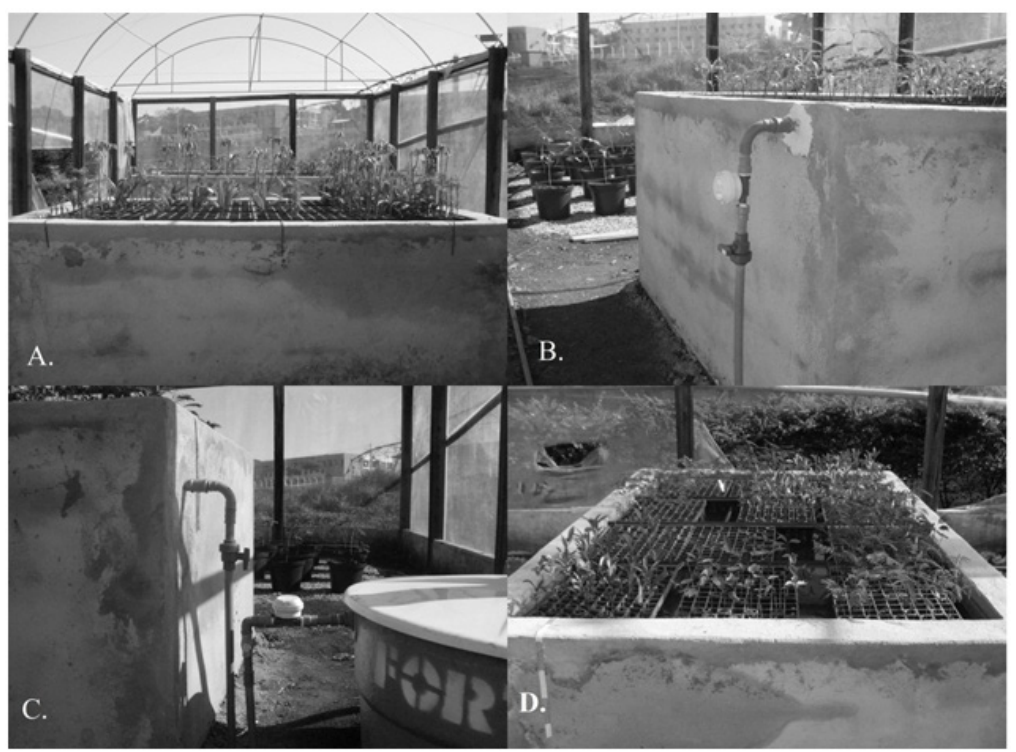

FIGURA 2: Detalhes dos tanques de subirrigação.

FIGURE 2: Overviews of sub-irrigation tanks. 
O sistema de alimentação dos tanques foi constituído por uma motobomba Schneider modelo $\mathrm{BC}-98$ com potência de $0,25 \mathrm{cv}$, que retirava a água de duas caixas d'água de 500 litros em fibra, cada uma destas ligada a um tanque de subirrigação.

A lâmina de água aplicada por tanque foi de $0,05 \mathrm{~m}$ a partir da parte inferior do tubetes. O tempo de irrigação de tubetes grandes era de 0,75 horas e de 0,5 horas para tubetes pequenos, tempos estes necessários para que a frente de umidade vinda por ascensão capilar chegasse à camada superior de substrato.

Esses tempos de irrigação representavam umidades de $0,55 \mathrm{~cm}^{3} \mathrm{~cm}^{-3}$ em tubetes grandes $\mathrm{e}$ $0,67 \mathrm{~cm}^{3} \mathrm{~cm}^{-3}$ em tubetes pequenos tendo o substrato $0,38 \mathrm{~cm}^{3} \mathrm{~cm}^{-3}$ de umidade inicial, correspondentes a tensões de $2,34 \mathrm{kPa}$ e $1,50 \mathrm{kPa}$, respectivamente, em tubetes contendo substrato sem plantas. A curva de retenção de água pelo substrato foi obtida com software SWRC versão 3.0 da ESALQ/USP, utilizando-se o modelo de Van Genuchten (1980) e pode ser observada na Figura 3.

Segundo a nomenclatura sugerida por López (2000) e destacada na Figura 3, a Porosidade Total do substrato utilizado era de $0,974 \mathrm{~cm}^{3} \mathrm{~cm}^{-3}$, Espaço de Aeração de $0,170 \mathrm{~cm}^{3} \mathrm{~cm}^{-3}$, Água Facilmente Disponível de $0,362 \mathrm{~cm}^{3} \mathrm{~cm}^{-3}$, Água de Reserva de $0,034 \mathrm{~cm}^{3} \mathrm{~cm}^{-3} \mathrm{e}$ Água Residual de $0,408 \mathrm{~cm}^{3} \mathrm{~cm}^{-3}$.

A água bombeada para os tanques era retirada por meio da mesma motobomba utilizada para a alimentação, retornando à sua caixa d'água correspondente.

Tanto na entrada quanto na saída de cada tanque foram instalados hidrômetros para

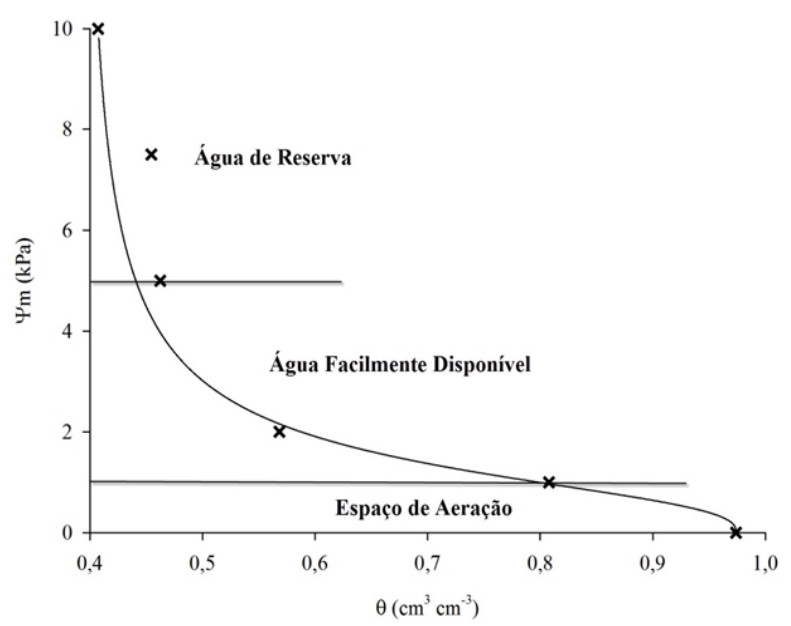

FIGURA 3: Curva de retenção de água do substrato. FIGURE 3: Substrate water retention curve. monitoramento exato da quantidade de água que entrou e saiu de cada unidade de subirrigação.

Para reduzir a perda de substrato nos tubetes no momento da drenagem da água, foram fixados na parte inferior de cada tubete, com auxílio de gomas elásticas, quadrados de aproximadamente $0,07 \mathrm{~m}$ de lado de Tule (manta tipo esponja). Esta medida foi tomada para que não houvesse perda de substrato durante as avaliações, o que poderia ser confundido com uma possível perda de água.

As bandejas de cada tanque foram pesadas, antes e após cada irrigação, obtendo-se pela diferença, a massa de água irrigada efetiva (Equação 5), que pôde ser convertida em volume irrigado efetivo (Equação 6).

$$
\begin{gathered}
M_{\text {aad }}=M_{\text {dirr }}-M_{\text {airr }} \\
V_{\text {aad }}=\frac{M_{\text {aad }}}{\rho_{\mathrm{H} 2 \mathrm{O}}}
\end{gathered}
$$

Em que: $\mathrm{M}_{\text {aad }}=$ massa de água adicionada à bandeja após a irrigação $(\mathrm{kg}) ; \mathrm{M}_{\text {dirr }}=$ massa da bandeja depois da irrigação $(\mathrm{kg}) ; \mathrm{M}_{\text {airr }}=$ massa da bandeja antes da irrigação $(\mathrm{kg}) ; \mathrm{V}_{\text {aad }}=$ volume irrigado efetivo $\left(\mathrm{m}^{3}\right)$; $\rho_{\mathrm{H} 2 \mathrm{O}}=$ densidade da água aplicada (valor assumido de $1000 \mathrm{~kg} \mathrm{~m}^{-3}$ ).

Em cada irrigação foram monitorados os volumes de entrada (Ve) e saída (Vs) de água dos tanques. A diferença entre estes caracterizou o volume irrigado. Após cada irrigação, foram aguardados trinta minutos para que houvesse a drenagem da água não fortemente aderida ao substrato. $\mathrm{O}$ volume de água perdido foi computado como sendo a soma da drenagem dos tubetes após a irrigação e o volume possivelmente evaporado dos tanques. O volume perdido foi obtido pela Equação 7.

$$
\mathrm{V}_{\mathrm{p}}=\left(\mathrm{V}_{\mathrm{e}}-\mathrm{V}_{\mathrm{s}}\right)-\mathrm{V}_{\mathrm{aadt}}
$$

Em que: $V_{p}=$ volume perdido por tanque $\left(\mathrm{m}^{3}\right)$; $\mathrm{V}_{\mathrm{e}}=$ volume de entrada no tanque $\left(\mathrm{m}^{3}\right) ; \mathrm{V}_{\mathrm{s}}=$ volume de saída no tanque $\left(\mathrm{m}^{3}\right) ;\left(\mathrm{V}_{\mathrm{e}}-\mathrm{V}_{\mathrm{s}}\right)=$ volume irrigado $\left(\mathrm{m}^{3}\right) ; \mathrm{V}_{\text {aadt }}=$ volume de água adicionado ao total de bandejas por tanque $\left(\mathrm{m}^{3}\right)$.

A porcentagem de água perdida por subirrigação foi obtida pela Equação 8 .

$$
\mathrm{P}_{\mathrm{sub}}=\frac{\mathrm{V}_{\mathrm{p}}}{\mathrm{V}_{\mathrm{e}}-\mathrm{V}_{\mathrm{s}}} \times 100
$$

Em que: $\mathrm{P}_{\text {sub }}=$ perda de água total (\%). 
A eficiência de aplicação da subirrigação pode ser definida pela Equação 9 .

$$
\mathrm{Ea}_{\text {sub }}=100-\mathrm{P}_{\text {sub }}
$$

Em que: $\mathrm{Ea}_{\text {sub }}=$ eficiência de aplicação da subirrigação (\%).

A massa de água retida por bandeja foi obtida com balança digital com precisão de 0,002 $\mathrm{kg}$ para massa até $6 \mathrm{~kg}$ e $0,005 \mathrm{~kg}$ para massas superiores. Foram realizadas, neste experimento, três repetições no tempo, representadas por irrigações subsequentes.

\section{RESULTADOS E DISCUSSÃO}

\section{Eficiência da microaspersão}

O resumo da Análise de Variância realizada nas avaliações das perdas diretas, perdas por percolação e eficiência de irrigação das espécies avaliadas cultivadas em tubetes grandes é apresentado na Tabela 1.

Os elevados valores de coeficiente de variação obtidos nos ensaios se devem ao esquema estatístico utilizado e também à baixa uniformidade de irrigação observada nos equipamentos. Segundo Pereira (2003), as medidas de uniformidade dependem somente do grau de dispersão com que a água é aplicada, enquanto as medidas de eficiência dependem tanto da uniformidade como da forma com que o sistema de irrigação é operado, ou seja, quantificam fisicamente a qualidade da irrigação.

Mesmo os valores de eficiência de irrigação sendo considerados iguais estatisticamente (Tabela 1), há uma grande lacuna entre a maior eficiência $(61,51 \%$, araucária irrigada pelo microaspersor MA-20) e a menor (11,93\%, microaspersor Rondo irrigando a espécie jerivá), apresentadas na Tabela 2 .

$\mathrm{Na}$ área do viveiro em que o microaspersor Rondo encontrava-se instalado, notou-se grande necessidade de manutenção deste, estando os

TABELA 1: Resumo da ANOVA realizada nas avaliações das perdas diretas, perdas por percolação e eficiência de irrigação em tubetes grandes.

TABLE 1: Summary of ANOVA performed on the assessments of direct losses, percolation losses and irrigation efficiency in large tubes.

\begin{tabular}{lcccc}
\hline \multirow{2}{*}{ Causas da variação } & \multirow{2}{*}{ GL } & \multicolumn{3}{c}{ Quadrado Médio e significância de F } \\
\cline { 3 - 5 } & & Perdas diretas & Perdas por ercolação & Eficiência \\
\hline Microaspersor (M) & 2 & $505,4024^{\text {ns }}$ & $111,2337^{\text {ns }}$ & $588,6409^{\text {ns }}$ \\
Erro a & 6 & 106,2888 & 215,6918 & 181,3407 \\
Espécie (E) & 2 & $238,3660^{\text {ns }}$ & $229,5855^{\text {ns }}$ & $475,4714^{\text {ns }}$ \\
M x E & 4 & $66,6083^{\text {ns }}$ & $60,6891^{\text {ns }}$ & $71,6307^{\text {ns }}$ \\
Erro b & 12 & 173,1522 & 132,1791 & 137,3785 \\
cv a & & 29,39 & 58,60 & 32,07 \\
cv b & & 37,51 & 45,87 & 27,91 \\
\hline
\end{tabular}

Em que: ns = não significativo; * = significativo ao teste de $\mathrm{F}$ a $5 \%$ de probabilidade; $\mathrm{cv}=$ coeficiente de variação.

TABELA 2: Eficiência de irrigação obtida nas espécies cultivadas em tubetes grandes em cada equipamento de irrigação.

TABLE 2: Irrigation efficiency obtained in the species cultivated in large tubes for each irrigation equipment.

\begin{tabular}{cccc}
\hline \multirow{2}{*}{ Espécie } & \multicolumn{3}{c}{ Eficiência de irrigação (\%) } \\
\cline { 2 - 4 } & MA-20 & IRS & Rondo \\
\hline Araucária & 61,51 & 46,17 & 34,08 \\
Jerivá & 47,34 & 40,28 & 11,93 \\
Cutieira & 58,32 & 62,62 & 46,91 \\
\hline
\end{tabular}


emissores em sua maioria com incrustações de lodo e entupimento visível, o que não permitia que as peças giratórias dos emissores realizassem seu movimento, concentrando o jato aspergido em um único ponto.

O resumo da Análise de Variância realizada para as avaliações das perdas diretas, por percolação da lâmina irrigada e a eficiência de irrigação nas espécies irrigadas cultivadas em tubetes pequenos, é apresentado na Tabela 3.

As perdas diretas médias, caracterizada pela água perdida sem mesmo haver o contato com o substrato, obtidas nos equipamentos de irrigação são apresentadas na Tabela 4. Nesta, os emissores IRS e Rondo apresentam maior perda direta média e o MA-20 tendo a menor porcentagem de perda direta da lâmina aplicada.

A partir de determinada fase de desenvolvimento, a densidade das mudas deve diminuir, sendo estas posicionadas de maneira intercalada nas bandejas que acomodam os tubetes. Esta técnica agrega qualidade às mudas, pois reduz a competição por luz, produzindo mudas com maior diâmetro do caulículo, mas resulta em menor eficiência de aplicação de água, por ocasionar perdas diretas.

As perdas por percolação médias por equipamento de irrigação em tubetes pequenos são apresentadas na Tabela 5. Nos emissores MA-20 e IRS foram obtidas as menores porcentagens de perda por percolação, com o microaspersor Rondo tendo quantidade superior aos demais, resultado explicado pelo excesso de lâmina aplicada por este em pontos isolados das bandejas irrigadas.

Avaliando-se as espécies cultivadas em tubetes pequenos, a espécie peroba-rosa apresentou maior perda por percolação média, como apresentado na Tabela 6.

Fica evidenciada na Tabela 7 a maior eficiência de irrigação nos emissores MA-20, seguido pelo IRS, na aplicação de água nas espécies cultivadas em tubetes pequenos. A eficiência média para o microaspersor Rondo foi $29,65 \%$.

As combinações dos tratamentos não influenciaram nas eficiências de aplicação para as espécies cultivadas em tubetes pequenos (Tabela 3 ). Porém, avaliando os resultados obtidos sem levar em consideração a inferência estatística, nota-se maior eficiência nas aplicações dos emissores MA20 e IRS, tendo a área com o emissor Rondo uma

TABELA 3: Resumo da ANOVA realizada nas avaliações de perda direta, perda por percolação e eficiência de irrigação em tubetes pequenos.

TABLE 3: Summary of ANOVA performed on the assessments of direct losses, percolation losses and irrigation efficiency in small tubes.

\begin{tabular}{ccccc}
\hline \multirow{2}{*}{ Causas da variação } & \multirow{2}{*}{ GL } & \multicolumn{3}{c}{ Quadrado Médio e significância de F } \\
\cline { 3 - 5 } & & Perda direta & Perda por percolação & Eficiência \\
\hline Microaspersor (M) & 2 & $289,3162^{*}$ & $1394,1808^{*}$ & $1980,4118^{*}$ \\
Erro a & 6 & 41,0312 & 117,7054 & 81,6197 \\
Espécie (E) & 2 & $4,9036^{\text {ns }}$ & $122,7862^{*}$ & $59,9314^{\text {ns }}$ \\
M x E & 4 & $40,6725^{\text {ns }}$ & $56,1367^{\text {ns }}$ & $105,2343^{\text {ns }}$ \\
Erro b & 12 & 41,3506 & 27,4301 & 58,6429 \\
cv a & & 21,81 & 44,28 & 18,78 \\
cv b & & 21,90 & 21,38 & 15,92 \\
\hline
\end{tabular}

Em que: $\mathrm{ns}=$ não significativo; $*$ = significativo ao teste de $\mathrm{F}$ a $5 \%$ de probabilidade; $\mathrm{cv}=$ coeficiente de variação.

TABELA 4: Perdas diretas médias encontradas por equipamento de irrigação em tubetes pequenos.

TABLE 4: Average direct losses by irrigation equipment obtained in small tubes.

\begin{tabular}{lcc}
\hline & Equipamento & Perda direta (\%) \\
\hline MA-20 & $15,57 \mathrm{~b}$ \\
IRS & $27,56 \mathrm{a}$ \\
Rondo & $31,49 \mathrm{a}$ \\
\hline
\end{tabular}

Em que: Médias seguidas de mesma letra não diferem estatisticamente ao teste de Scott-Knott a 5\% de probabilidade. 
eficiência de uso da água muito baixa (Tabela 8).

Santiago et al. (2004) avaliaram a eficiência de aplicação em sistema de microaspersão instalado no solo na cultura do repolho, e obtiveram uma média por setor de $85,82 \%$, maior que o obtido em todos os tratamentos.

Salvador (2010), avaliando a eficiência de irrigação em viveiros para produção de porta enxertos em citrus, encontrou eficiências médias de irrigação variando entre $40 \%$ a $74 \%$ na fase de sementeira.

As baixas eficiências de irrigação em todos os tratamentos avaliados (Tabelas 2 e 8 ) podem ser explicadas pelo manejo de irrigação adotado pelo viveiro, pelo sistema produtivo de mudas em tubetes, em função dos espaços vazios nas bandejas susceptíveis à perda de água e pelos baixos valores de uniformidade de aplicação de água, o que gera áreas do viveiro com deficit de irrigação e outras superirrigadas, provocando grandes perdas por

TABELA 5: Perdas médias por percolação encontradas por equipamento de irrigação em tubetes pequenos. TABLE 5: Average percolation losses by irrigation obtained equipment in small tubes.

\begin{tabular}{|c|c|}
\hline Equipamento & Perda por percolação (\%) \\
\hline MA-20 & $6,61 \mathrm{~b}$ \\
\hline IRS & $14,44 \mathrm{~b}$ \\
\hline Rondo & 38,86 a \\
\hline
\end{tabular}

Em que: Médias seguidas de mesma letra não diferem estatisticamente ao teste de Scott-Knott a 5\% de probabilidade.

TABELA 6: Perdas médias por percolação encontradas por espécie em tubetes pequenos.

TABLE 6: Average percolation losses by species obtained in small tubes.

\begin{tabular}{lc}
\hline \multicolumn{1}{c}{ Equipamento } & Perda por percolação (\%) \\
\hline Mutamba & $16,68 \mathrm{a}$ \\
Angico-vermelho & $18,05 \mathrm{a}$ \\
Peroba-rosa & $25,19 \mathrm{~b}$ \\
\hline Em que: Médias seguidas de mesma letra não diferem estatisticamente ao teste de Scott-Knott a $5 \%$ de probabilidade.
\end{tabular}

TABELA 7: Eficiências médias encontradas por equipamento de irrigação em tubetes pequenos.

TABLE 7: Average efficiencies by irrigation equipment at small tubes.

\begin{tabular}{lcc}
\hline & Equipamento & Eficiência (\%) \\
\hline MA-20 & $77,82 \mathrm{a}$ \\
IRS & $58,00 \mathrm{~b}$ \\
Rondo & $29,65 \mathrm{c}$ \\
\hline
\end{tabular}

Em que: Médias seguidas de mesma letra não diferem estatisticamente ao teste de Scott-Knott a 5\% de probabilidade.

TABELA 8: Eficiência de irrigação obtida nas espécies cultivadas em tubetes pequenos em cada equipamento de irrigação.

TABLE 8: Irrigation efficiency obtained in the species cultivated in small tubes in each irrigation equipment.

\begin{tabular}{lccc}
\hline \multirow{2}{*}{ Espécie } & \multicolumn{3}{c}{ Equipamento } \\
\cline { 2 - 4 } & MA-20 & IRS & Rondo \\
\hline Mutamba & 77,12 & 66,84 & 32,47 \\
Angico-vermelho & 81,03 & 65,02 & 21,86 \\
Peroba-rosa & 75,29 & 42,15 & 34,62 \\
\hline
\end{tabular}

Ci. Fl., v. 26, n. 2, abr.-jun., 2016 
percolação.

\section{Eficiência da subirrigação}

Ambos os tanques de subirrigação apresentaram grande eficiência de irrigação, como pode ser visto na Tabela 9. Assim como no caso da uniformidade, a eficiência no tanque de tubetes pequenos foi superior à avaliada em tubetes grandes.

Apesar de um grande volume de entrada de água por tanque em cada irrigação (aproximadamente $0,210 \mathrm{~m}^{3}$ para tanque de tubetes pequenos e 0,200 $\mathrm{m}^{3}$ para o tanque de tubetes grandes), os volumes irrigados médios foram de $0,51 \%$ (tubetes grandes) e $0,63 \%$ (tubetes pequenos) do total de entrada.

Durante o esvaziamento dos tanques, assim que os tubetes deixavam de estar submersos, era iniciada a drenagem do substrato. Uma parte da água drenada voltava para os reservatórios ao invés de ser considerada uma perda, fato que garante maior eficiência ao sistema.

Mesmo observando-se uma porcentagem muito pequena de perdas, haverá menores perdas por evaporação, quanto maior for a densidade de plantas nos tanques, por haver maior cobertura pelas folhas das plantas da lâmina de água aplicada. Outro fator que reduz as perdas por evaporação são as condições climáticas do local no momento da irrigação.

Pode-se inferir que as perdas por drenagem nos tubetes grandes são maiores que nos tubetes pequenos, pela presença de um maior gradiente de potencial gravitacional entre o topo do tubete e seu fundo, já que o tubete grande possui $0,16 \mathrm{~m}$ de altura, enquanto o menor possui $0,10 \mathrm{~m}$, o que gera menor eficiência de irrigação no tanque de tubetes grandes.

As eficiências de irrigação avaliadas nos tanques de subirrigação foram superiores às encontradas no viveiro de mudas florestais nativas em Itutinga - MG, em microaspersores na posição invertida e por Santiago et al. (2004) em avaliação de microaspersão no cultivo do repolho.
Salvador (2010) avaliou um equipamento de irrigação por capilaridade sem recirculação de água, desenvolvido para produção de porta-enxertos de mudas cítricas, em que para 54 mudas, houve uma aplicação de 7,63 litros de água e perdas por percolação de 6,30 litros, o que representa uma eficiência de $17,44 \%$.

\section{CONCLUSÕES}

A eficiência de irrigação dos sistemas de microaspersão avaliados no viveiro de mudas florestais de Itutinga é afetada pela uniformidade de aplicação de água, manutenção deficitária e pelo sistema produtivo de mudas de espécies florestais em tubetes.

Os tanques de subirrigação mostraram-se como uma alternativa interessante para irrigação de mudas de espécies florestais, apresentando alta eficiência para os dois tamanhos de tubetes avaliados.

\section{REFERÊNCIAS BIBLIOGRÁFICAS}

AHMED, A. K.; CRESSWELL, G. C.; HAIGH, A. M. Comparison of sub-irrigation and overhead irrigation of tomato and lettuce seedlings. Journal of Horticultural Science and Biotechnology, Ashford, v. 75, p. 350 -354, 2000.

BOLFE, E. L. et al. Avaliação da classificação digital de povoamentos florestais em imagens de satélite através de índices de Acurácia. Revista Árvore, Viçosa, v. 28, n. 1, p. 85-90, 2004.

CHANSEETIS, C. et al. Application of capillary hydroponic system to the lettuce growing under tropical climate conditions. Acta Horticulturae, Leuven, v. 548, p. 401-407, 2001.

DUMROESE, R. K. et al. Exponential fertilization of Pinus monticola seedlings: nutrient uptake efficiency, leaching fractions, and early outplanting performance. Canadian Journal of Forest Research, Ottawa, v. 35, p. 2961-2967, 2005.

Nursery waste water. The problem and possible

TABELA 9: Volume irrigado, volume irrigado efetivo e eficiência de irrigação dos tanques de subirrigação. TABLE 9: Irrigated volume, effective irrigated volume and irrigation efficiency of sub-irrigation tanks.

\begin{tabular}{lccc}
\hline \multicolumn{1}{c}{ Tanque } & Volume irrigado (L) & Volume irrigado efetivo (L) & Eficiência (\%) \\
\hline Tubetes grandes & 1,023 & 0,925 & 90,42 \\
Tubetes pequenos & 1,315 & 1,212 & 92,17 \\
\hline
\end{tabular}


remedies. In: NATIONAL PROCEEDINGS, FOREST AND CONSERVATION NURSERY ASSOCIATION 36., 1995, Portland. Proceedings... Portland: USDA Forest Service, 1995. p. 89-97.

Subirrigation reduces water use, nitrogen loss, and moss growth in a container nursery. Native Plants Journal, Madison, v. 7, n. 3, p. 253-261, 2006. FRIZZONE, J.A.; DOURADO NETO, D. Avaliação de sistemas de irrigação. In: MIRANDA, J. H.; PIRES, R. C. M. Irrigação. Jaboticabal: FUNEP, 2003. p. 573-652.

JUNTENEN, M. L. et al. Ground water quality: leaching of nitrogen and phosphorus during production of forest seedlings in containers. Journal of Environmental Quality, Madison, v. 31, p. 1868-1874, 2002.

LÓPEZ, C. C. Fertirrigacion cultivos horticolas y ornamentales. 2. ed. Madrid: Mundi-Prensa, 2000. $475 \mathrm{p}$.

MOLITOR, H. The european perspective with emphasis on subirrigation and recirculation of water and nutrients. Acta Horticulturae, Leuven, v. 272, p. 165-174, 1990.

PEREIRA, G. M. Aspersão convencional. In: MIRANDA, J. H.; PIRES, R. C. M. Irrigação. 2. ed. Piracicaba: FUNEP, 2003. 703 p.

SALVADOR, C. A. Sistema de irrigação por capilaridade na produção de porta - enxertos de mudas cítricas na fase de sementeira. 2010. 105 p. Dissertação (Mestrado em Engenharia Agrícola) - Universidade Estadual de Campinas, Campinas, 2010.

SANTIAGO, F. S. et al. Avaliação de parâmetros hidráulicos e manejo da irrigação por microaspersão em área de assentamento. Engenharia Agrícola, Jaboticabal, v. 24, n. 3, p. 632-643, 2004.

SOCCOL, O. J. et al. Performance analysis of a trickle irrigation subunit installed in an apple orchard. Brazilian Archives of Biology and Technology, Curitiba, v. 45, n. 4, p. 525-530, 2002. STAMATO JÚNIOR, R. P. Condições meteorológicas e consumo de água por mudas cítricas em ambiente protegido. 2007. 68 p. Dissertação (Mestrado em Tecnologia da Produção Agrícola) - Instituto Agronômico de Campinas, Campinas, 2007.

STRONG, S. S. et al. Cultivar and spacing effects on transmission of Phytophthora parasitica in an ebb-and-flow subirrigation system. Plant Disease, Davis, v. 81, n. 1, p. 89-95, 1997.

TOSHIAKI, A. M. et al. Spatial distribution of ions in groundwater under agricultural land. Journal of Irrigation and Drainage Engineering, Newark, v. 130, n. 6, p. $468,2004$.

VAN GENUCHTEN, M. T. A closed-form equation for predicting the hydraulic conductivity of unsaturated soils. Soil Science Society of America Journal, Madison, v. 44, p. 892-898, 1980. 